\title{
Cough Expired Volume and Cough Peak Flow Rate Estimation Based on GA-BP Method
}

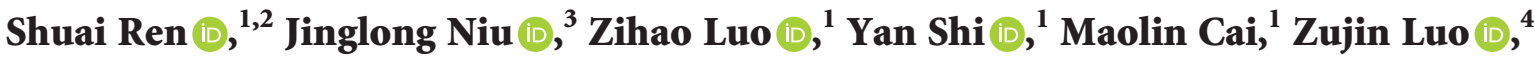 \\ and Qihui Yu $\mathbb{D i D}^{2}$ \\ ${ }^{1}$ School of Automation Science and Electrical Engineering, Beihang University, Beijing 100191, China \\ ${ }^{2}$ The State Key Laboratory of Fluid Power and Mechatronic Systems, Zhejiang University, Hangzhou 310027, China \\ ${ }^{3}$ North Automatic Control Technology Institute, Taiyuan, Shanxi 030006, China \\ ${ }^{4}$ Department of Respiratory and Critical Care Medicine, \\ Beijing Engineering Research Center of Respiratory and Critical Care Medicine, Beijing Institute of Respiratory Medicine, \\ Beijing Chao-Yang Hospital, Capital Medical University, Beijing 100043, China
}

Correspondence should be addressed to Shuai Ren; renshuai@buaa.edu.cn and Yan Shi; yesoyou@gmail.com

Received 21 October 2019; Revised 14 January 2020; Accepted 3 February 2020; Published 26 February 2020

Academic Editor: Danilo Comminiello

Copyright (c) 2020 Shuai Ren et al. This is an open access article distributed under the Creative Commons Attribution License, which permits unrestricted use, distribution, and reproduction in any medium, provided the original work is properly cited.

Cough is a respiratory protective behavior for clearing the secretion. The cough process can be characterized by three features which are cough peak flow rate, peak velocity time, and cough expired volume. The cough expired volume (CEV) and the cough peak flow rate (CPFR) are important for medical diagnosis and cough effectiveness assessment. In this study, the CEV and CPFR values of 700 healthy participants were measured and collected by using a portable pulmonary function device. The gender, age, height, weight, and smoking status information of the 700 participants were also collected. Meanwhile, the integration of backpropagation neural network and genetic algorithm (GA-BP) method was developed to estimate CEV and CPFR values. The results showed that the estimation accuracy of GA-BP method exceeds $90 \%$, which indicates that the GA-BP method could be effectively used for CEV and CPFR value estimation. Furthermore, the method proposed in this paper could be useful for medical diagnosis and medical device development.

\section{Introduction}

Cough is a kind of respiratory reflex behavior. When the respiratory tract is stimulated by inflammation, dust, or some particulate matters, cough behavior is performed to clear respiratory secretions to keep the respiratory tract clean and unobstructed [1-5]. Because of the high pressure difference between the inside and outside of the thoracic cavity, a high airflow rate is generated to impose a great shear force on the surface of secretions and propel them to the mouth [6].

According to previous studies, the cough process continued about $0.4 \sim 0.6 \mathrm{~s}$ and can be characterized by three parameters which are cough peak flow rate (CPFR), peak velocity time (PVT), and cough expired volume (CEV) [7-10]. The CEV and CPFR are the total exhausted air volume and the maximum airflow rate measured in atmosphere normal reference during the whole cough process, respectively.

The cough expired volume (CEV) and the cough peak flow rate (CPFR) are important for medical diagnosis, cough effectiveness assessment, and extubation decision [11-13]. However, as for the patients with mechanical ventilation, neuromuscular disease, or other diseases which impairs the cough ability, the CEV and CPFR values cannot be obtained and used for medical diagnosis. Therefore, establishing a relationship between the CEV, CPFR values and human physical information could be used for medical diagnosis for these patients. If the physical information is obtained, the CEV and CPFR values will be estimated.

Previous studies have developed the relations between CEV and CPFR values and human genders, heights, and 
weights. Leiner et al. found that the CPFR is related to the height and age of human [14]. Mahajan et al. and Singh et al. involved the gender as an influence factor and developed relations between CPFR, CEV, and PVT $[8,9]$. Their research involved 100 healthy and nonsmoking volunteers (50 females and 50 males) and showed a direct relationship between CPFR and CEV values [8]. The results showed that the maximum value of $\mathrm{CEV}$ reached $5 \mathrm{~L}$ with an average of $3 \mathrm{~L}$. Zhu et al. measured the CEV values of three healthy subjects and found that the variation range from 0.8 to $2.2 \mathrm{~L}$ with an average of $1.4 \mathrm{~L}$ [15]. Gupta et al. investigated 25 healthy subjects (12 females and 13 males) and developed a first-order relation between CEV, CPFR values and genders, heights, and weights through the linear regression analysis method [7]. The results are performed as follows:

$$
\begin{aligned}
\operatorname{CPFR}\left(\frac{\mathrm{L}}{\mathrm{s}}\right)= & -8.8980+6.3925 h(\mathrm{~m}) \\
& +0.0346 w(\mathrm{~kg}), \quad \text { for male, } \\
\operatorname{CPFR}\left(\frac{\mathrm{L}}{\mathrm{s}}\right)= & -3.9702+4.6265 h(\mathrm{~m}), \quad \text { for female } \\
\operatorname{CEV}(\mathrm{L})= & 0.138 \operatorname{CPFR}\left(\frac{\mathrm{L}}{\mathrm{s}}\right)+0.2983(\mathrm{~m}), \text { for male } \\
\operatorname{CEV}(\mathrm{L})= & 0.0204 \operatorname{CPFR}\left(\frac{\mathrm{L}}{\mathrm{s}}\right)-0.043(\mathrm{~m}), \text { for female. }
\end{aligned}
$$

Brandimore et al. established a linear relation among CEV values, airflow rates, and number of coughs through analyzing the measured data of 25 participants (14 females and 11 males with an average of 23 years old). The results demonstrated significant linear relationships between expired volume, the total number of coughs, and cough airflow rates [6]. Particle velocimetry (PIV) method has been also used to estimate ranges of cough velocities. Chao et al. collected the average velocity of 50 coughs from eleven healthy volunteers ( 3 men and 8 women). The estimated maximum cough velocities of male and female were $13.2 \mathrm{~m} / \mathrm{s}$ and $10.2 \mathrm{~m} / \mathrm{s}$, respectively [16]. VanSciver et al. performed over twenty-nine nonsmoking healthy volunteers (ten male and nineteen female volunteers) to obtain and analyze the cough velocity. The results showed that there is no correlation between cough velocity and sex and weight [10].

In this study, 700 healthy participants were involved. The CEV values, CPFR values, genders, heights, weights, ages, and smoking status were measured and recorded. Meanwhile, the integration of backpropagation neural network and genetic algorithm, which is called the GA-BP method was developed to estimate CEV and CPFR values.

\section{Materials and Methods}

2.1. Experiment Setup. The CEV and CPFR values were measured by using a portable pulmonary function device (Contec Ltd.), which are presented in Figure 1. The CEV and CPFR values acquisition range from 0 to $10 \mathrm{~L}$ and $0 \sim 16 \mathrm{~L} / \mathrm{s}$, respectively. The acquisition errors are within $\pm 0.05 \mathrm{~L}$ and $0.2 \mathrm{~L} / \mathrm{s}$, respectively. A disposable connector is installed in the front of the device during the collection. The human subjects hold the connector with their mouths and cough forcefully. After a single cough, the CEV and CPFR values will be displayed on the device screen and stored in the device.

All the participants were receiving the training of how to use this device before measurement. Sitting posture was adopted during measurement.

2.2. Ethical Statement. The CEV, CPFR values, and physical information of 700 human subjects were obtained by the doctor at the Chao Yang Hospital. All the human subjects were agreed to conduct these measurements and signed the informed content. The Chao Yang Hospital ethics committee and human subjects have approved these data collection (Approval number: 20175241).

2.3. Backpropagation Neural Network. BP neural network is a multilayer feedforward neural network with the forward signal transmission and reverse error transmission and could be used to estimate any nonlinear relations through training [17-20]. Typically, the BP neural network consists of the input layer, hidden layer, and output layer. The input signals are processed layer by layer from the input layer through the hidden layer to the output layer. If the expected output is not achieved, the signals transfer to backpropagation. According to the prediction error, the neural network weights and threshold values adjust to obtain the expected output values [21-24].

In this study, five inputs which represent gender, height, weight, age, and smoking status, and two outputs which represent CEV and CPFR value are set up in the BP neural network. The structure of the BP neural network is presented in Figure 2. The neuron number of hidden layers is set to 11 based on the Hecht-Nelson method.

2.4. BP Neural Network Improved by Genetic Algorithm. Although BP neural network can obtain a good estimated result through the training process, the training time is too long and the results may converge to local optimal values. Genetic Algorithm (GA) is a parallel random search optimization method, which imitates the natural genetic mechanism and Darwin's principle of biological evolution [25-27]. Therefore, the BP neural network is improved by genetic algorithm (GA) to solve this problem, which is called GA-BP [28-30]. The GA-BP algorithm is used to search for the most preferable weights and thresholds of neural network. The whole operation process includes initialization, calculating fitness values, selection, crossover, and mutation. This process repeats until the end condition is satisfied.

The data set which consists of the connection weights and thresholds of neural network is regarded as an individual. As shown in Figure 3, the real number coding was used to create the initial values for each individual which consists of $\omega_{i j}, a, \omega_{j k}$, and $b$. The $\omega_{i j}$ and $\omega_{j k}$ represented the 


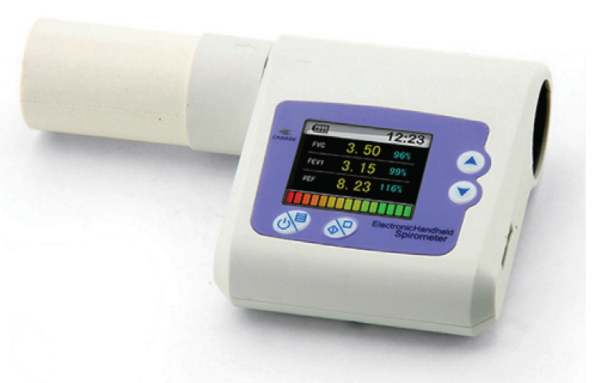

Figure 1: Portable pulmonary function device (Contec Ltd.). The CEV and CPFR values can be displayed on the screen and stored in the device. The data can be transmitted to the computer through Bluetooth function.

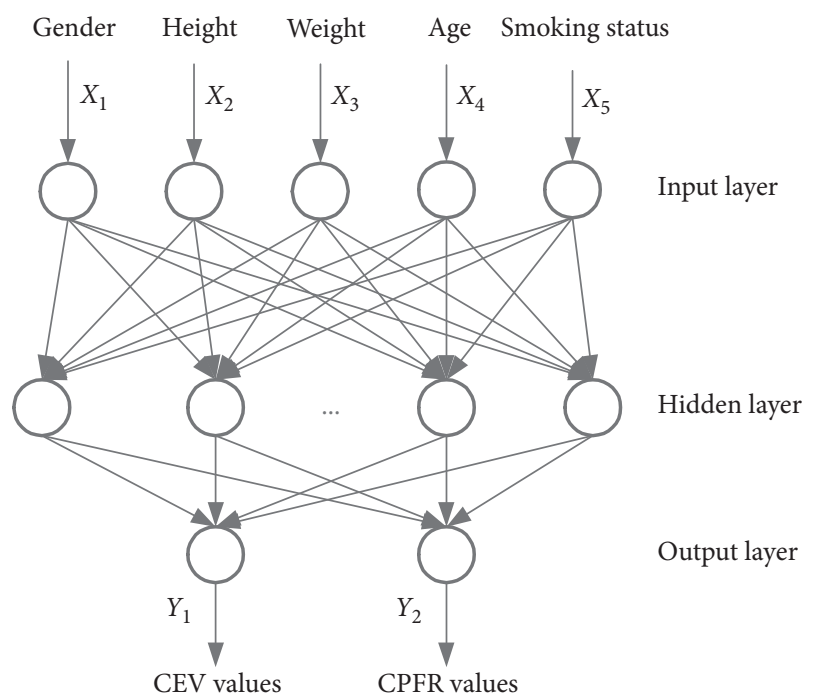

Figure 2: The BP neural network structure used in this study. A three-layer structure was adopted. There are five neurons in the input layer, eleven neurons in the hidden layer, and two neurons in the output layer.

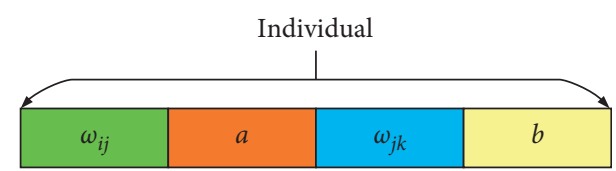

FIgURE 3: The diagram of real number coding of individual. The weights $\omega_{i j}$ and $\omega_{j k}$ and thresholds $a$ and $b$ are arranged serially in a single individual.

weights between the input layer and hidden layer and the weights between the hidden layer and output layer, respectively. The $a$ and $b$ represented the thresholds of the hidden layer and output layer, respectively. The number of individuals was set ten in this study.

The absolute error between predicted and expected output of BP neural network was used as the individual fitness value in this study. The fitness function is as below:

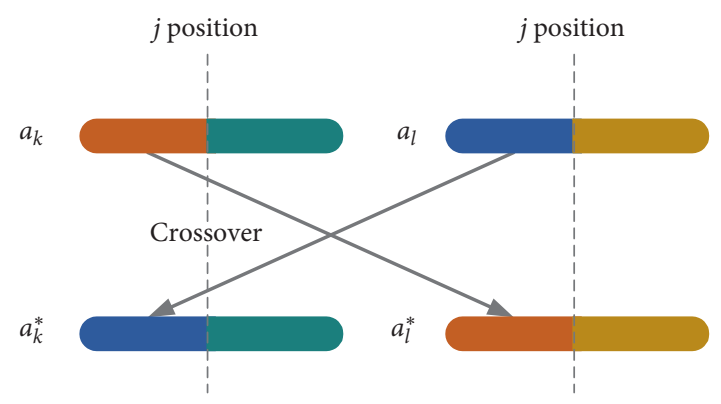

Figure 4: An example of crossover operation. The crossover operation for individual $a_{k}$ and $a_{l}$ performs at the $j$ position. Part of the chromosome information has been exchanged for $a_{k}$ and $a_{l}$.

$$
E=\sum_{i=1}^{m}\left|Y_{i}-O_{i}\right|,
$$

where $E$ is the individual fitness value, $m$ is the number of neurons in output layer, and $Y_{i}$ and $O_{i}$ are the predicted output and expected output of the network, respectively.

The goal of selection is that individuals with lower fitness have a greater chance to inherit to the next generation. The roulette method was used for selection operation in this study, as shown in the following formula:

$$
\begin{aligned}
& f_{i}=\frac{k}{E_{i}}, \\
& p_{i}=\frac{f_{i}}{\sum_{j=1}^{N} f_{j}},
\end{aligned}
$$

where $p$ is the chosen probability of each individual, $k$ is the coefficient, and $N$ is the number of individuals.

The crossover probability was set 0.5 . The crossover operation for individual $a_{k}$ and $a_{l}$ at the $j$ position was presented in equation (4). The diagram is shown in Figure 4.

$$
\begin{aligned}
& a_{k j}^{*}=a_{k j} \cdot(1-\alpha)+a_{l j} \cdot \alpha, \\
& a_{l j}^{*}=a_{l j} \cdot(1-\alpha)+a_{k j} \cdot \alpha,
\end{aligned}
$$

where $\alpha$ is a random number between [0 1].

The mutation probability was set 0.4 and the diagram is shown in Figure 5. The new chromosome $a_{i j}^{*}$ is calculated through equation (5).where $a_{\max }$ and $a_{\min }$ are the upper bound and lower bound of gene $a_{i j}$, respectively. The $r_{2}$ is a random number, $g$ is the current iteration number, $G_{\max }$ is the maximum evolution number, and $r$ is a random number between [0 1].

$$
\begin{aligned}
& a_{i j}^{*}= \begin{cases}a_{i j}+\left(a_{i j}-a_{\max }\right) f(g), & r>0.5, \\
a_{i j}+\left(a_{\min }-a_{i j}\right) f(g), & r<0.5,\end{cases} \\
& f(g)=r_{2}\left(1-\frac{g}{G_{\max }}\right)^{2},
\end{aligned}
$$




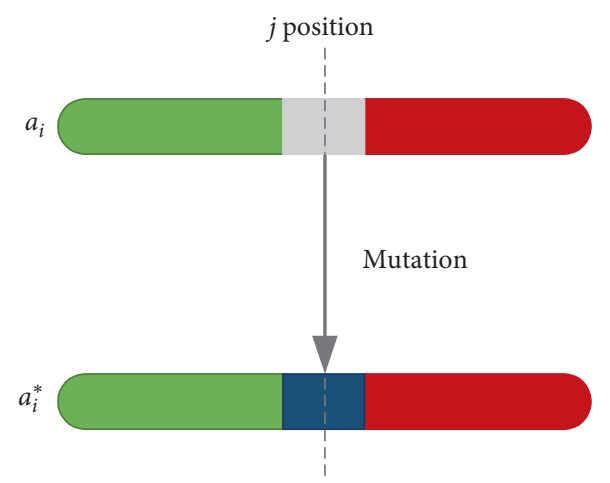

Figure 5: An example of mutation operation. The chromosome information at $j$ position of $a_{i}$ has been altered.

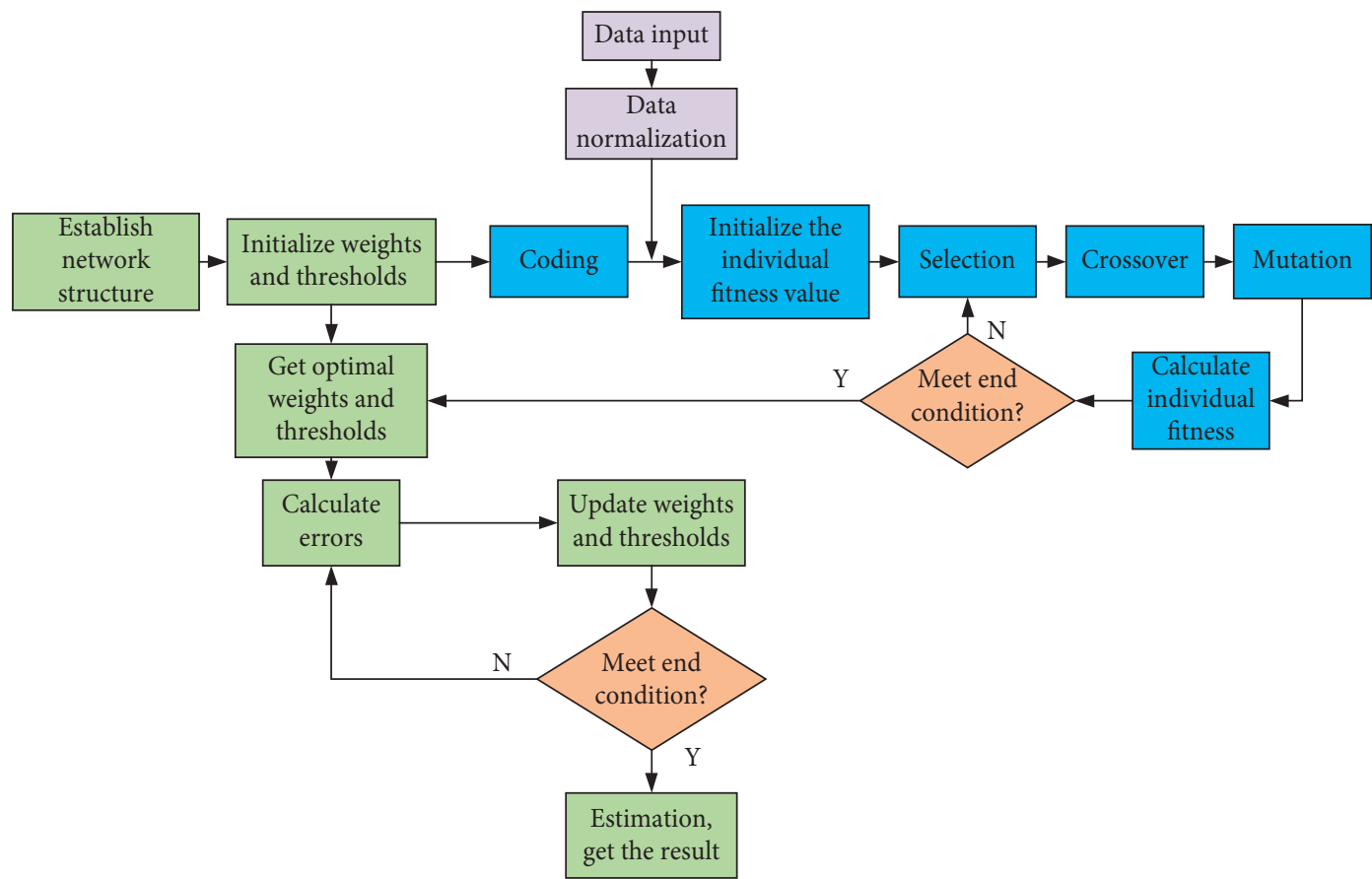

FIGURE 6: The operation process of GA-BP. The GA-BP starts with GA which optimizes the initial values of weight and threshold of the BP neural network. Then, the BP neural network begins training with the optimized weights and thresholds until the end condition is satisfied.

The iteration was set 40 . The operation process of GA-BP is presented in Figure 6.

\section{Results}

The statistical results of collected physical information (gender, age, height, weight, and smoking status), CEV, and CPFR values of 700 human subjects are presented in Table 1.

In order to testify the GA-BP method, the ten times tenfold cross-validations method was adopted. 700 groups of data were randomly divided into tenfolds, each fold contains 70 groups of data. Ninefold data were used to train the GA-BP network. The remaining onefold data is used for validation. Through ten different random groupings and exchanging the training and test data, we conducted ten times tenfold cross-
Table 1: Statistical results of data for 700 subjects.

\begin{tabular}{lc}
\hline Parameters & Value \\
\hline Number of males & 430 \\
Number of females & 270 \\
Number of smokers & 106 \\
Number of nonsmokers & 594 \\
Average of age & 23.71 \\
Standard deviation of age & 8.36 \\
Average of height $(\mathrm{cm})$ & 171.01 \\
Standard deviation of height $(\mathrm{cm})$ & 7.68 \\
Average of weight $(\mathrm{kg})$ & 66.60 \\
Standard deviation of weight $(\mathrm{kg})$ & 13.41 \\
Average of CEV $(\mathrm{L})$ & 1.54 \\
Standard deviation of CEV $(\mathrm{L})$ & 0.77 \\
Average of CPFR $(\mathrm{L} / \mathrm{s})$ & 6.25 \\
Standard deviation of CPFR $(\mathrm{L} / \mathrm{s})$ & 1.72
\end{tabular}


TABLe 2: Statistical results of data for ten times tenfold cross-validations (test 1 to test 5).

\begin{tabular}{|c|c|c|c|c|c|c|c|c|c|c|}
\hline \multirow[b]{2}{*}{ Parameters } & \multicolumn{2}{|c|}{ Test 1} & \multicolumn{2}{|c|}{ Test 2} & \multicolumn{2}{|c|}{ Test 3} & \multicolumn{2}{|c|}{ Test 4} & \multicolumn{2}{|c|}{ Test 5} \\
\hline & $\begin{array}{c}\text { Training } \\
\text { group }\end{array}$ & $\begin{array}{c}\text { Validation } \\
\text { group }\end{array}$ & $\begin{array}{c}\text { Training } \\
\text { group }\end{array}$ & $\begin{array}{c}\text { Validation } \\
\text { group }\end{array}$ & $\begin{array}{c}\text { Training } \\
\text { group }\end{array}$ & $\begin{array}{c}\text { Validation } \\
\text { group }\end{array}$ & $\begin{array}{c}\text { Training } \\
\text { group }\end{array}$ & $\begin{array}{l}\text { Validation } \\
\text { group }\end{array}$ & $\begin{array}{l}\text { Training } \\
\text { group }\end{array}$ & $\begin{array}{c}\text { Validation } \\
\text { group }\end{array}$ \\
\hline $\begin{array}{l}\text { Number of } \\
\text { males }\end{array}$ & 390 & 40 & 391 & 39 & 384 & 46 & 391 & 39 & 389 & 41 \\
\hline $\begin{array}{l}\text { Number of } \\
\text { females }\end{array}$ & 240 & 30 & 239 & 31 & 246 & 24 & 239 & 31 & 241 & 29 \\
\hline $\begin{array}{l}\text { Number of } \\
\text { smokers }\end{array}$ & 95 & 11 & 97 & 9 & 96 & 10 & 93 & 13 & 94 & 12 \\
\hline $\begin{array}{l}\text { Number of } \\
\text { nonsmokers }\end{array}$ & 535 & 59 & 533 & 61 & 534 & 60 & 537 & 57 & 536 & 58 \\
\hline $\begin{array}{l}\text { Average of } \\
\text { age }\end{array}$ & 23.87 & 22.30 & 23.73 & 23.50 & 23.70 & 23.86 & 23.72 & 23.67 & 23.53 & 25.33 \\
\hline $\begin{array}{l}\text { Standard } \\
\text { deviation of } \\
\text { age }\end{array}$ & 8.41 & 7.70 & 8.48 & 7.15 & 8.43 & 7.64 & 8.34 & 8.52 & 8.29 & 8.74 \\
\hline $\begin{array}{l}\text { Average of } \\
\text { height }(\mathrm{cm})\end{array}$ & 171.02 & 170.89 & 171.00 & 171.07 & 171.07 & 170.47 & 171.03 & 170.74 & 171.00 & 171.01 \\
\hline $\begin{array}{l}\text { Standard } \\
\text { deviation of } \\
\text { height }(\mathrm{cm})\end{array}$ & 7.62 & 8.25 & 7.64 & 8.07 & 7.86 & 5.84 & 7.70 & 7.56 & 7.67 & 7.84 \\
\hline $\begin{array}{l}\text { Average of } \\
\text { weight }(\mathrm{kg})\end{array}$ & 66.76 & 65.09 & 66.66 & 65.99 & 66.60 & 66.56 & 66.62 & 66.39 & 66.70 & 65.71 \\
\hline $\begin{array}{l}\text { Standard } \\
\text { deviation of } \\
\text { weight }(\mathrm{kg})\end{array}$ & 13.08 & 15.99 & 13.50 & 12.53 & 13.42 & 13.30 & 13.39 & 13.54 & 13.61 & 11.33 \\
\hline $\begin{array}{l}\text { Average of } \\
\text { CEV (L) }\end{array}$ & 1.55 & 1.46 & 1.54 & 1.61 & 1.54 & 1.58 & 1.55 & 1.51 & 1.54 & 1.57 \\
\hline $\begin{array}{l}\text { Standard } \\
\text { deviation of } \\
\text { CEV (L) }\end{array}$ & 0.76 & 0.82 & 0.77 & 0.76 & 0.78 & 0.65 & 0.77 & 0.80 & 0.77 & 0.75 \\
\hline $\begin{array}{l}\text { Average of } \\
\text { CPFR (L/s) }\end{array}$ & 6.26 & 6.08 & 6.23 & 6.37 & 6.25 & 6.24 & 6.26 & 6.15 & 6.24 & 6.29 \\
\hline $\begin{array}{l}\text { Standard } \\
\text { deviation of } \\
\operatorname{CPFR}(\mathrm{L} / \mathrm{s})\end{array}$ & 1.71 & 1.85 & 1.72 & 1.70 & 1.76 & 1.37 & 1.71 & 1.79 & 1.71 & 1.78 \\
\hline
\end{tabular}

TABLe 3: Statistical results of data for ten times tenfold cross-validations (test 6 to test 10).

\begin{tabular}{|c|c|c|c|c|c|c|c|c|c|c|}
\hline \multirow[b]{2}{*}{ Parameters } & \multicolumn{2}{|c|}{ Test 1} & \multicolumn{2}{|c|}{ Test 2} & \multicolumn{2}{|c|}{ Test 3} & \multicolumn{2}{|c|}{ Test 4} & \multicolumn{2}{|c|}{ Test 5} \\
\hline & $\begin{array}{c}\text { Training } \\
\text { group }\end{array}$ & $\begin{array}{l}\text { Validation } \\
\text { group }\end{array}$ & $\begin{array}{c}\text { Training } \\
\text { group }\end{array}$ & $\begin{array}{l}\text { Validation } \\
\text { group }\end{array}$ & $\begin{array}{l}\text { Training } \\
\text { group }\end{array}$ & $\begin{array}{l}\text { Validation } \\
\text { group }\end{array}$ & $\begin{array}{l}\text { Training } \\
\text { group }\end{array}$ & $\begin{array}{l}\text { Validation } \\
\text { group }\end{array}$ & $\begin{array}{c}\text { Training } \\
\text { group }\end{array}$ & $\begin{array}{l}\text { Validation } \\
\text { group }\end{array}$ \\
\hline $\begin{array}{l}\text { Number of } \\
\text { males }\end{array}$ & 385 & 45 & 382 & 48 & 382 & 48 & 388 & 42 & 388 & 42 \\
\hline $\begin{array}{l}\text { Number of } \\
\text { females }\end{array}$ & 245 & 25 & 248 & 22 & 248 & 22 & 242 & 28 & 242 & 28 \\
\hline $\begin{array}{l}\text { Number of } \\
\text { smokers }\end{array}$ & 99 & 7 & 95 & 11 & 94 & 12 & 100 & 6 & 91 & 15 \\
\hline $\begin{array}{l}\text { Number of } \\
\text { nonsmokers }\end{array}$ & 531 & 63 & 535 & 59 & 536 & 58 & 530 & 64 & 539 & 55 \\
\hline $\begin{array}{l}\text { Average of } \\
\text { age }\end{array}$ & 23.62 & 24.53 & 23.63 & 24.47 & 23.73 & 23.50 & 23.73 & 23.57 & 23.86 & 22.39 \\
\hline $\begin{array}{l}\text { Standard } \\
\text { deviation of } \\
\text { age }\end{array}$ & 8.21 & 9.51 & 8.21 & 9.58 & 8.49 & 7.00 & 8.27 & 9.10 & 8.42 & 7.67 \\
\hline $\begin{array}{l}\text { Average of } \\
\text { height }(\mathrm{cm})\end{array}$ & 171.02 & 170.87 & 170.83 & 172.60 & 170.93 & 171.64 & 171.12 & 169.97 & 171.03 & 170.79 \\
\hline $\begin{array}{l}\text { Standard } \\
\text { deviation of } \\
\text { height }(\mathrm{cm})\end{array}$ & 7.68 & 7.68 & 7.67 & 7.63 & 7.63 & 8.09 & 7.67 & 7.71 & 7.69 & 7.62 \\
\hline $\begin{array}{l}\text { Average of } \\
\text { weight }(\mathrm{kg})\end{array}$ & 66.66 & 66.04 & 66.21 & 70.08 & 66.42 & 68.15 & 66.61 & 66.52 & 66.73 & 65.43 \\
\hline
\end{tabular}


TABle 3: Continued.

\begin{tabular}{|c|c|c|c|c|c|c|c|c|c|c|}
\hline \multirow[b]{2}{*}{ Parameters } & \multicolumn{2}{|c|}{ Test 1} & \multicolumn{2}{|c|}{ Test 2} & \multicolumn{2}{|c|}{ Test 3} & \multicolumn{2}{|c|}{ Test 4} & \multicolumn{2}{|c|}{ Test 5} \\
\hline & $\begin{array}{c}\text { Training } \\
\text { group }\end{array}$ & $\begin{array}{l}\text { Validation } \\
\text { group }\end{array}$ & $\begin{array}{c}\text { Training } \\
\text { group }\end{array}$ & $\begin{array}{l}\text { Validation } \\
\text { group }\end{array}$ & $\begin{array}{c}\text { Training } \\
\text { group }\end{array}$ & $\begin{array}{l}\text { Validation } \\
\text { group }\end{array}$ & $\begin{array}{c}\text { Training } \\
\text { group }\end{array}$ & $\begin{array}{l}\text { Validation } \\
\text { group }\end{array}$ & $\begin{array}{c}\text { Training } \\
\text { group }\end{array}$ & $\begin{array}{l}\text { Validation } \\
\text { group }\end{array}$ \\
\hline $\begin{array}{l}\text { Standard } \\
\text { deviation of } \\
\text { weight (kg) }\end{array}$ & 13.50 & 12.57 & 13.26 & 14.19 & 13.48 & 12.62 & 13.39 & 13.58 & 13.43 & 13.18 \\
\hline $\begin{array}{l}\text { Average of } \\
\text { CEV (L) }\end{array}$ & 1.55 & 1.46 & 1.52 & 1.73 & 1.53 & 1.67 & 1.56 & 1.44 & 1.56 & 1.43 \\
\hline $\begin{array}{l}\text { Standard } \\
\text { deviation of } \\
\mathrm{CEV} \text { (L) }\end{array}$ & 0.77 & 0.75 & 0.76 & 0.81 & 0.77 & 0.77 & 0.77 & 0.78 & 0.77 & 0.73 \\
\hline $\begin{array}{l}\text { Average of } \\
\text { CPFR (L/s) }\end{array}$ & 6.26 & 6.10 & 6.20 & 6.65 & 6.21 & 6.54 & 6.27 & 6.03 & 6.27 & 6.01 \\
\hline $\begin{array}{l}\text { Standard } \\
\text { deviation of } \\
\operatorname{CPFR}(\mathrm{L} / \mathrm{s})\end{array}$ & 1.73 & 1.65 & 1.70 & 1.86 & 1.71 & 1.83 & 1.73 & 1.64 & 1.74 & 1.56 \\
\hline
\end{tabular}

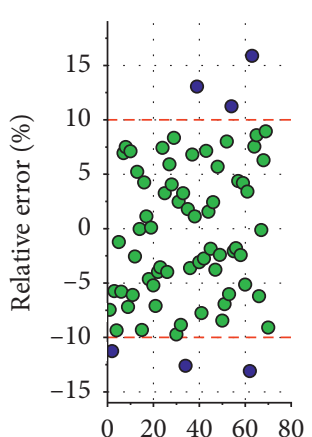

(a)

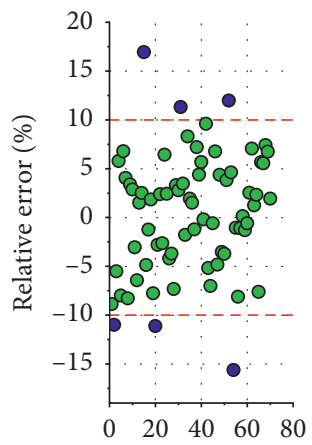

(f)

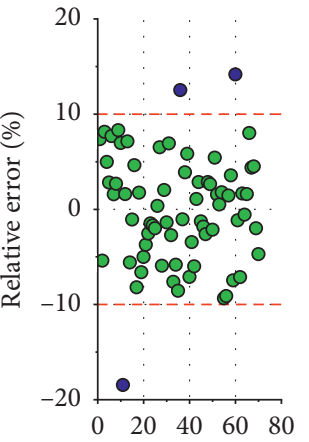

(b)

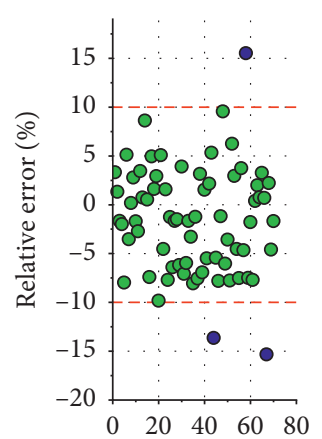

(g)

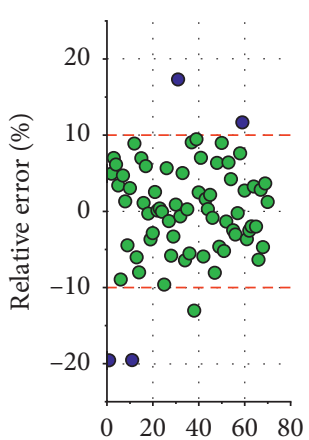

(c)

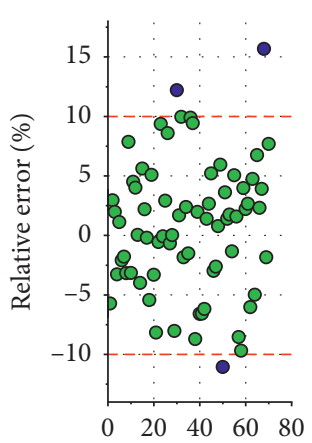

(h)

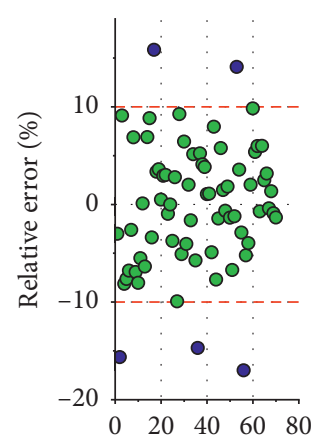

(d)

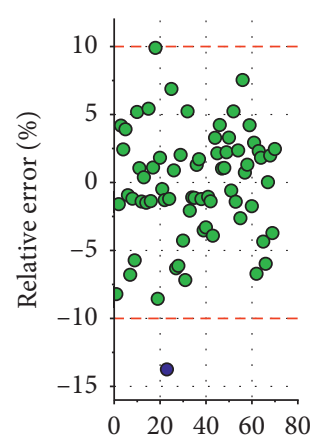

(i)

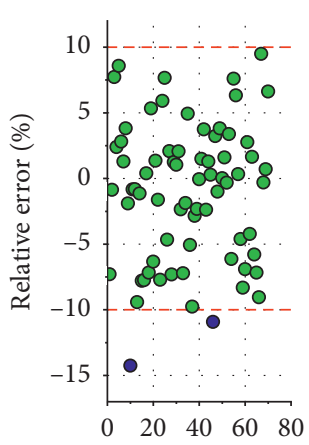

(e)

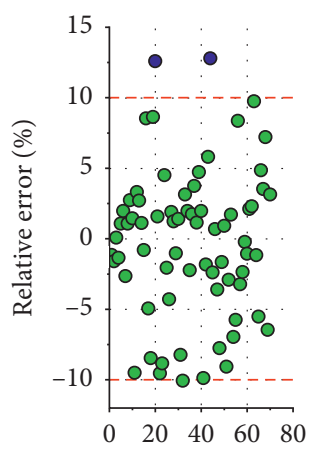

(j)

- Relative error within

- Relative error beyond $10 \%$

FIgURE 7: The relative errors between estimated and test CEV values in ten times tenfold cross-validations. The relative errors within 10\% were marked green circles while beyond $10 \%$ were marked blue circles. (a) Test (1). (b) Test (2). (c) Test (3). (d) Test (4). (e) Test (5). (f) Test (6). (g) Test (7). (h) Test (8). (i) Test (9). (j) Test (10).

validations. The statistical results of data for ten times tenfold cross-validations from test 1 to test 10 are presented in Tables 2 and 3 .

The relative errors between estimated and test values for CEV and CPFR in ten times tenfold cross-validations are calculated and presented in Figures 7 and 8, respectively.

\section{Discussion}

There were 700 participants (430 males and 270 females) involved in this study. There were 106 smokers, accounting for about $15 \%$ of the total. The age, height, weight, CEV, and CPFR values were collected and analyzed. The average of 


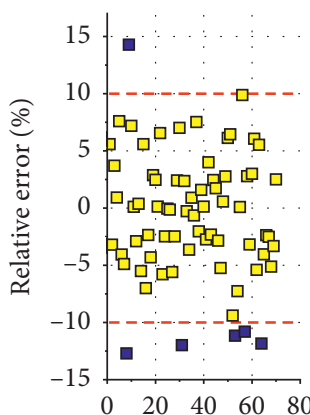

(a)

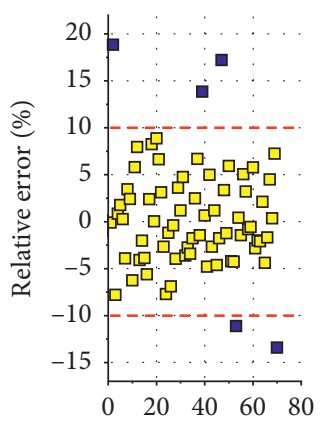

(f)

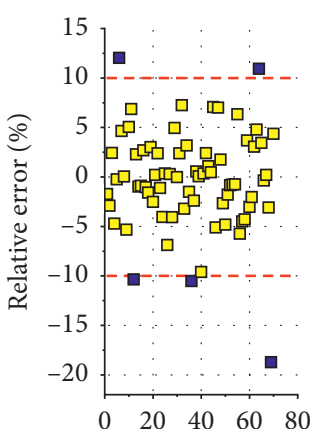

(b)

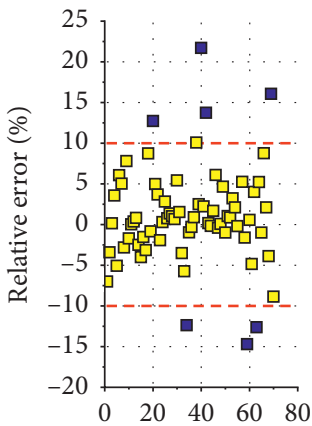

(g)

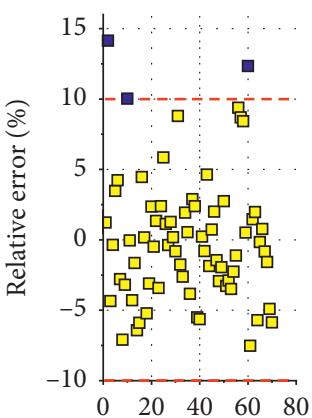

(c)

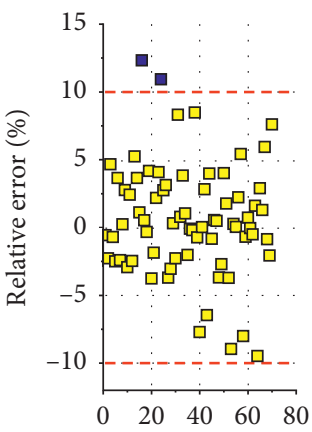

(h)

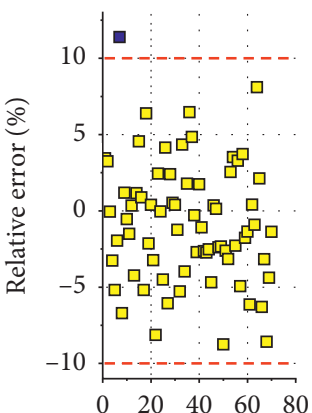

(d)

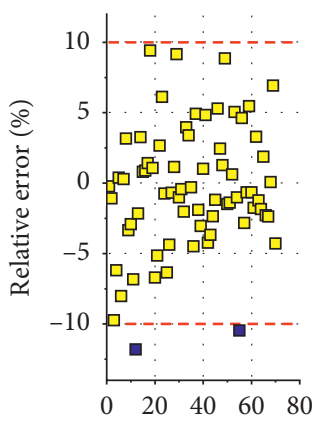

(i)

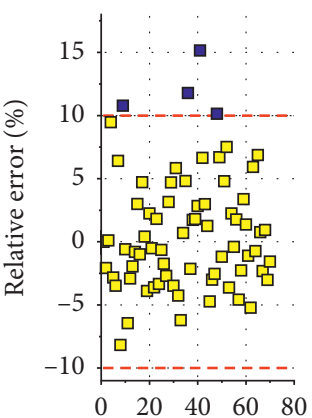

(e)

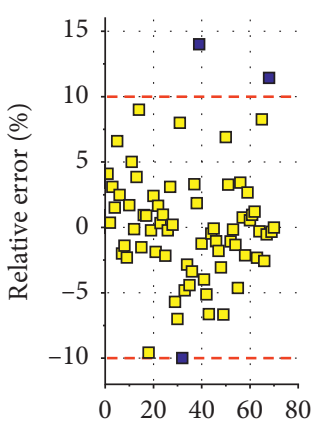

(j)

․ Relative error within $10 \%$

- Relative error beyond $10 \%$

FIgURE 8: The relative errors between estimated and test CPFR values in ten times tenfold cross-validations. The relative errors within $10 \%$ were marked yellow squares while beyond $10 \%$ were marked blue squares. (a) Test (1). (b) Test (2). (c) Test (3). (d) Test (4). (e) Test (5). (f) Test (6). (g) Test (7). (h) Test (8). (i) Test (9). (j) Test (10).

TABLE 4: The accuracy of ten times validations and the average values for CEV and CPFR values estimations.

\begin{tabular}{|c|c|c|c|c|}
\hline $\begin{array}{l}\text { Test } \\
\text { group }\end{array}$ & $\begin{array}{l}\text { CEV estimation } \\
\text { accuracy (\%) }\end{array}$ & $\begin{array}{l}\text { The average of CEV estimation } \\
\text { accuracy (\%) }\end{array}$ & $\begin{array}{l}\text { CPFR estimation } \\
\text { accuracy (\%) }\end{array}$ & $\begin{array}{c}\text { The average of CPFR estimation } \\
\text { accuracy (\%) }\end{array}$ \\
\hline Test (1) & 91.43 & \multirow{10}{*}{95.00} & 91.43 & \multirow{10}{*}{94.57} \\
\hline Test (2) & 95.71 & & 92.86 & \\
\hline Test (3) & 94.29 & & 94.29 & \\
\hline Test (4) & 92.86 & & 98.57 & \\
\hline Test (5) & 97.14 & & 94.29 & \\
\hline Test (6) & 91.43 & & 92.86 & \\
\hline Test (7) & 95.71 & & 91.43 & \\
\hline Test (8) & 95.71 & & 97.14 & \\
\hline Test (9) & 98.57 & & 97.14 & \\
\hline Test (10) & 97.14 & & 95.71 & \\
\hline
\end{tabular}

CEV and CPFR were $1.54 \mathrm{~L}$ and $6.25 \mathrm{~L} / \mathrm{s}$, respectively. It is adapt to the statistical results of physical information of participants which presents a young state.

The ten times tenfold cross-validations method was adopted to verify the GA-BP method. From Tables 2 and 3, we found that the average and standard deviation values of age, height, weight, $\mathrm{CEV}$, and CPFR values of training groups were approximate with that of validation groups in all ten times validations. It indicated that all the training and validations groups were selected randomly and the estimated results were reliable.

It is considered that the estimated value is acceptable and relatively accurate when the absolute error is within $10 \%$ in this study. From the ten times validation results in Figures 7 and 8, we find that the relative errors of a large number of test samples are within $10 \%$ for both CEV and CPFR values. The accuracy of ten times validations and the average values for CEV and CPFR estimations are calculated and presented in Table 4. From Table 4, we found that the accuracy of CEV and CPFR value estimations exceeded the $90 \%$ in all ten times validations. The averages of CEV and CPFR estimation accuracy were $95 \%$ and $94.57 \%$, respectively. The results indicated that the GA-BP method has a high accuracy and could be effectively used for $\mathrm{CEV}$ values and CPFR values estimation.

Considering the low sampling frequency of the portable pulmonary function device, the PVT value estimation is not 
completed in this study. Even the estimation accuracy is high under current condition and more data especially in a large span of age, height, weight, and other physical information should be involved and used for improving the generalization ability.

\section{Conclusions}

The heights, weights, ages, smoking status, CEV, and CPFR values of 700 participants were collected and analyzed in this paper. The GA-BP method which integrates backpropagation neural network and genetic algorithm was developed to estimate the CEV and CPFR values. Additionally, the ten times tenfold cross-validation method was adopted to testify the GA-BP method. The results show that the estimation accuracy of GA-BP method used for CEV and CPFR values both exceeds $90 \%$. The averages of CEV and CPFR estimation accuracy reached $95 \%$ and $94.57 \%$, respectively. The estimation results verified the accuracy of the GA-BP method.

In the future study, the PVT value estimations will be completed. More information such as compliance and resistance will be measured and used in the GA-BP method to improve the generalization ability.

\section{Data Availability}

The datasets generated and analyzed during the current study are available in the Baidu cloud disk repository (https://pan. baidu.com/s/1NLTUx81PO817LocGWpzJ1A\&shfl=sharepset; code: 0qv1).

\section{Conflicts of Interest}

The authors declare that they have no conflicts of interest.

\section{Acknowledgments}

This research was funded by the National Natural Science Foundation of China (Grant 51575020) and China Postdoctoral Science Foundation (Grant 2019M660391). It was also funded by Open Foundation of the State Key Laboratory of Fluid Power and Mechatronic Systems (Grant nos. GZKF201920 and GZKF-201804).

\section{References}

[1] J. B. Fink, "Forced expiratory technique, directed cough, and autogenic drainage," Respiratory Care, vol. 52, no. 9, pp. 1210-1223, 2007.

[2] C. De Boeck and R. Zinman, "Cough versus chest physiotherapy: a comparison of the acute effects on pulmonary function in patients with cystic fibrosis," American Review of Respiratory Disease, vol. 129, no. 1, pp. 182-184, 1984.

[3] K. A. Hardy, "A review of airway clearance: new techniques, indications, and recommendations," Respiratory Care, vol. 39, no. 5, pp. 440-455, 1994.

[4] M. Chatwin, E. Ross, N. Hart, A. H. Nickol, M. I. Polkey, and A. K. Simonds, "Cough augmentation with mechanical insufflation/exsufflation in patients with neuromuscular weakness," European Respiratory Journal, vol. 21, no. 3, pp. 502-508, 2003.

[5] A. Szeinberg, E. Tabachnik, N. Rashed et al., "Cough capacity in patients with muscular dystrophy," Chest, vol. 94, no. 6, pp. 1232-1235, 1988.

[6] A. E. Brandimore, M. S. Troche, J. E. Huber, and K. W. Hegland, "Respiratory kinematic and airflow differences between reflex and voluntary cough in healthy young adults," Frontiers in Physiology, vol. 6, p. 284, 2015.

[7] J. K. Gupta, C.-H. Lin, and Q. Chen, "Flow dynamics and characterization of a cough," Indoor Air, vol. 19, no. 6, pp. 517-525, 2009.

[8] R. P. Mahajan, P. Singh, G. E. Murty, and A. R. Aitkenhead, "Relationship between expired lung volume, peak flow rate and peak velocity time during a voluntary cough manoeuvre," British Journal of Anaesthesia, vol. 72, no. 3, pp. 298-301, 1994.

[9] P. Singh, R. P. Mahajan, G. E. Murty, and A. R. Aitkenhead, "Relationship of peak flow rate and peak velocity time during voluntarv couzhinc," British Journal of Anaesthesia, vol. 74, no. 6, pp. 714-716, 1995.

[10] M. VanSciver, S. Miller, and J. Hertzberg, "Particle image velocimetry of human cough," Aerosol Science and Technology, vol. 45, no. 3, pp. 415-422, 2011.

[11] M. King, G. Brock, and C. Lundell, "Clearance of mucus by simulated cough," Journal of Applied Physiology, vol. 58, no. 6, pp. 1776-1782, 1985.

[12] N. Srour, C. LeBlanc, J. King, and D. A. McKim, "Lung volume recruitment in multiple sclerosis," PLoS One, vol. 8, no. 1, Article ID e56676, 2013.

[13] J. M. Lamb, G. E. Murty, R. M. Slater, and A. R. Aitkenhead, "Postoperative laryngeal function assessed by tussometry," British Journal of Anaesthesia, vol. 70, no. 4, pp. 478-479, 1993.

[14] G. C. Leiner, S. Abramowitz, M. J. Small, and V. B. Stenby, "Cough peak flow hate," The American Journal of the Medical Sciences, vol. 251, no. 2, pp. 211-214, 1966.

[15] S. Zhu, S. Kato, and J.-H. Yang, "Study on transport characteristics of saliva droplets produced by coughing in a calm indoor environment," Building and Environment, vol. 41, no. 12, pp. 1691-1702, 2006.

[16] C. Y. H. Chao, M. P. Wan, L. Morawska et al., "Characterization of expiration air jets and droplet size distributions immediately at the mouth opening," Journal of Aerosol Science, vol. 40, no. 2, pp. 122-133, 2009.

[17] H. Xiao, M. Butlin, I. Tan, A. Qasem, and A. P. Avolio, "Estimation of pulse transit time from radial pressure waveform alone by artificial neural network," IEEE Journal of Biomedical and Health Informatics, vol. 22, no. 4, pp. 11401147, 2017.

[18] Y. Shi, H. Liu, Y. Wang, M. Cai, and W. Xu, "Theory and application of audio-based assessment of cough," Journal of Sensors, vol. 2018, Article ID 9845321, 10 pages, 2018.

[19] R. J. Oweis, E. W. Abdulhay, A. Khayal, and A. Awad, "An alternative respiratory sounds classification system utilizing artificial neural networks," Biomedical Journal, vol. 38, no. 2, p. 153, 2015.

[20] Y. Shi, G. Wang, J. Niu et al., "Classification of sputum sounds using artificial neural network and wavelet transform," International Journal of Biological Sciences, vol. 14, no. 8, pp. 938-945, 2018.

[21] J. Cheng, X. Wang, T. Si et al., "Maximum burning rate and fixed carbon burnout efficiency of power coal blends predicted 
with back-propagation neural network models," Fuel, vol. 172, pp. 170-177, 2016.

[22] X.-L. Xie, F. Gao, X.-Y. Huang, C. Huang, and J. Li, "Numerical optimization of flow noises for mufflers based on the improved BP neural network," Journal of Vibroengineering, vol. 18, no. 4, pp. 2626-2640, 2016.

[23] D. Fan, J. Yang, J. Zhang et al., "Effectively measuring respiratory flow with portable pressure data using back propagation neural network," IEEE Journal of Translational Engineering in Health and Medicine, vol. 6, pp. 1-12, 2018.

[24] J. Cheng, X. Wang, T. Si, F. Zhou, J. Zhou, and K. Cen, "Ignition temperature and activation energy of power coal blends predicted with back-propagation neural network models," Fuel, vol. 173, pp. 230-238, 2016.

[25] W. Liang, P. Zhang, X. Chen, M. Cai, and D. Yang, "Genetic algorithm (GA)-based inclinometer layout optimization," Sensors, vol. 15, no. 4, pp. 9136-9155, 2015.

[26] L. Wang, A. Kolios, T. Nishino, P.-L. Delafin, and T. Bird, "Structural optimisation of vertical-axis wind turbine composite blades based on finite element analysis and genetic algorithm," Composite Structures, vol. 153, pp. 123-138, 2016.

[27] J. S. Reynolds, W. T. Goldsmith, J. B. Day et al., "Classification of voluntary cough airflow patterns for prediction of abnormal spirometry," IEEE Journal of Biomedical and Health Informatics, vol. 20, no. 3, pp. 963-969, 2016.

[28] D. J. Montana and L. Davis, "Training feedforward neural networks using genetic algorithms," in Proceedings of the Joint Conference on Artificial Intelligence (IJCAI), vol. 1, Detroit, MI, USA, August 1989.

[29] G. Zhu, P. Zhang, T. Tshukudu, J. Yin, G. Fan, and X. Zheng, "Forecasting traffic-related nitrogen oxides within a street canyon by combining a genetic algorithm-back propagation artificial neural network and parametric models," Atmospheric Pollution Research, vol. 6, no. 6, pp. 1087-1097, 2015.

[30] D.-Z. Huang, R.-X. Gong, and S. Gong, "Prediction of wind power by chaos and BP artificial neural networks approach based on genetic algorithm," Journal of Electrical Engineering and Technology, vol. 10, no. 1, pp. 41-46, 2015. 